\title{
Challenges Encountered by Physical Education Teachers in \\ Online Teaching in Times of COVID-19 Pandemic
}

\author{
1 \\ Maricar C. Tegero \\ maricartegero@lnu.edu.ph \\ Leyte Normal University, P.Paterno St.,Tacloban City, 6500,Philippines
}

\begin{abstract}
Since the COVID-19 Pandemic has impacted every aspect of human life, and schools across the country have been closed due to the risk of spreading the virus, online teaching has emerged as a major alternative pedagogical strategy, especially among state colleges and universities. This article discusses a study that looked at the challenges encountered by PE teachers in the COVID-19 pandemic. A qualitative study employing phenomenological procedures to collect and analyze the data was used. The difficulties of operating online physical education classes for the first time included: methodological challenges, comprising the effects of the delivery of quality education and the time-consuming checking of outputs; technical challenges, resulting from poor internet connection, online modalities/platforms used, and online teaching distractions; and personal health concerns, comprising physical health issues, mental health issues, and social health issues. The study also revealed the coping mechanisms of the Physical Education teachers in online teaching. To address the identified problems and facilitate the efficient operation of online Physical Education classes, changes in strategic learning methods are needed to better understand online Physical Education characteristics and thereby better communicate the value of Physical Education. Physical Education teachers, through a variety of difficulties and crises, learn to cope with technical challenges and continue to run the class in virtual mode.
\end{abstract}

Keywords: Challenges Encountered; COVID-19 Pandemic; Online Teaching; Physical Education Teachers

\section{Introduction}

COVID-19 has been declared a pandemic by the World Health Organization as a current threat to humanity. This pandemic has successfully forced the global shutdown of several activities, including educational activities, resulting in a massive university crisis response migration, with online learning serving as the educational platform (Adedoyin \& Soykan, 2020). Teachers have tasks and responsibilities that are not easily transferable when they need to change from a face-to-face learning system in the classroom to an online learning system coupled with online learning experiences that have never been implemented before. During the implementation of online learning, there were learning issues of inequality and obstacles (Murphy, 2020). Inaccessible technology, inadequate infrastructure, a sudden paradigm shift, an inappropriate teacher-student ratio, and faculty under preparedness were some of the challenges that higher education institutions faced. (Dubey and Mishra, Gupta, and Shree, 2020; Pandey, 2020).

The pedagogical and technical abilities of teachers should be enhanced. As students transition from the four corners of the classroom to the boundaries of virtual reality, every learning institution must assess how effective online learning is in delivering quality education and outcomes-based education to students (Basilaia \& Kvavadze, 2020). The Commission on Higher Education granted academic freedom to HEIs in 
the higher education sector, requiring them to use available distance learning, e-learning, and other alternative modes of delivery to students.

PE teachers cannot deny that teaching their students in the midst of a pandemic is a difficult task. These issues arise as a result of a lack of technological resources, educational pedagogy, and even physical, mental, and socio-economic issues that affect the teaching-learning process. The purpose of this study is to help other Physical Education teachers recognize the challenges they face. As a result, this study looks into the challenges that teachers face when teaching physical education classes and suggests ways to improve future physical education classes.

The findings can be used as a foundation for future research and to help revitalize physical education classes because no other study has been done on the problems that Physical Education faces in state colleges and universities. The challenge of providing all students with a high-quality, equitable, and affordable education would set a new standard in education and improve educational preparation and health. As a result, this paper was written to provide a clear picture of the current educational mainstream.

\subsection{Research Questions}

In order to elucidate the experiences of Physical Education teachers amidst pandemic, this study sought to answer the following questions:

1. What are the challenges encountered by the Physical Education teachers doing online teaching during the COVID-19 pandemic?

2. What are the coping mechanisms of physical education teachers teaching online in times of COVID-19 pandemic?

\section{Methodology}

\subsection{Design}

A qualitative study approach focused on phenomenological procedures was used to collect and analyze the data. The study "turned to the essence of lived experience" of research participants' online physical education classes, exploring the experience of conducting these classes, discussing, and reflecting on their efficient activity and challenges.

\subsection{Environment}

This study was carried out at a state university. Since the aim of the study was to assess the challenges that teachers face while teaching Physical Education, as well as the interventions that have been introduced to overcome those challenges, the participating school was eager to see the findings in order to prepare for future research.

\subsection{Participants}

There were ten (10) Physical Education teachers who volunteered their time and efforts to participate in this study. A purposive sampling was used to select PE teachers for personal interviews because they could contribute statements and responses relative to the phenomenon.

\subsection{Instrument}

The primary research instrument in this study was an interview schedule focusing on the challenges faced by Physical Education teachers during the pandemic. Data were gathered in stages, with informal, 
conversational, and semi-structured interviews used to elicit detailed information from participants. This interview technique made them feel at ease and at ease when answering the questions. The data were analyzed in accordance with standard protocols for evaluating observation objects and indicators (Braun and Clarke, 2006).

\subsection{Data Collection Procedure}

The interview was scheduled around the convenience of the participants. In most cases, thorough interviewing is required to ensure a credible study. For the interview, the researcher used a voice recorder. The interview, which consisted of open-ended questions, was audio-recorded, and completely transcribed. The transcripts acted as the framework for evaluating the participants' verbalizations about their online teaching experiences. I double-checked each transcript when listening to the audiotapes to ensure accuracy. In addition, each interview subject was given a copy of the transcripts to review to ensure truthfulness. The interview was conducted using the language with which they are most comfortable.

\subsection{Data Analysis}

In this research, the narrative accounts of the informants were interpreted using Inductive Thematic Analysis, which followed the steps of the Colaizzi Method. The step-by-step procedure for evaluating the data was as follows: First, each informant's transcript was read and re-read to get a general understanding of the content of their struggles as well as their coping mechanisms in teaching Physical Education during this pandemic. Second, important statements were reported on a separate sheet for each transcript, with their lines noted. Definitively, important statements were grouped into sub-themes. The fourth step was to break down sub-themes into themes. Fifth, the study's findings were incorporated into a comprehensive summary of the phenomena under investigation. The fundamental structure of the phenomenon was outlined in the sixth phase, and the research informants were asked to validate the findings by comparing the researcher's descriptive results with their difficulties and coping mechanisms as Physical Education teachers in online teaching during the pandemic.

\subsection{Results and Discussions}

During the analysis, challenges encountered and coping mechanisms adopted by teachers teaching Physical Education were identified. Correspondingly, in each of the core themes, sub-themes were also classified, which are summarized below with relevant quotes from the participants.

\section{Challenges Encountered by Physical Education Teachers}

It is defined in this study that obstacles to knowledge acquisition by teaching Physical Education online have been referred to as "challenges encountered." These were broken down into themes, which are as follows: Methodological challenges, online teaching technical challenges, and health challenges and concerns In addition, the themes into sub-themes are divided based on the different issues that emerge from the period and arrangement of teaching physical education online. In the quarantined and locked down areas, education administrators are urging teachers and facilitators to collaborate and exchange "know-how" and digital infrastructures for teaching online, according to the literature (Czerniewicz, 2020). Emergency remote teaching (ERT) is a temporary transfer in instructional delivery to an alternative delivery mode due to crisis circumstances (Hodges et al., 2020), such as COVID-19, in comparison to interactions that are well prepared from the outset and configured to be online. 


\section{Theme 1. Methodological Challenges}

The first theme under the challenges faced by PE teachers is " These challenges were presented as factors from the participants' perspective. It involves problems with the effects on the delivery of quality education and the time-consuming checking of outputs. Adjustment and participation in the new framework were seen as stumbling blocks to the creation and introduction of online learning, and there were a variety of concerns with the length and structure of learning sessions.

Sub-theme 1.1: Effects in the Delivery of Quality Education. The study highlighted that the effects in the delivery of quality education is one of the methodological challenges. The following are some of the participants' experiences to this issue:

"I am just concerned about the delivery of the lessons to my students. I feel that I am not teaching the proper execution of the skills because I cannot see their real performance while doing the task. "

- (PE TC)

"I observed that there is a communication gap between my students and the teacher. They need more clarification for some of the lecture content and the modules, and those points were left unexplained because of miscommunication.

- (PE TE)

"This is another challenge for me because, once I announce our scheduled online classes to the class, only a few people will show up, and the rest of the class will have their own excuses for not attending. I am not interested in teaching in an online setting where, out of 40 students, only 10 will attend. The standard of education is in jeopardy. "

$-(\mathrm{PE} \mathrm{TH})$

Teacher competencies in both pedagogy and technology should be reinforced. From this transition to the new normal, from the four corners of the classroom to the borders of virtual reality, every learning institution needs to study how successful online learning is in providing quality education and outcomesbased education to students (Basilaia \& Kvavadze, 2020). One such issue is the potential difference in access to digital learning resources for students that reside at home rather than on or near campus in an online delivery context (Raes et al., 2019).

The study found that teachers are concerned about providing quality physical education in this time of pandemic.They had already spent time and effort on designing their online teaching strategies as well as planning lessons for online delivery, but the students were unable to compensate for their efforts. It is emphasized that physical education teachers must do a better job of communicating the theories and applications of real physical activity.Still, it is expected of them to provide a more practical educational activity for online teaching in physical education. Teachers' gestures have shown that they prefer performance tasks that analyze similar features to be performed face-to-face rather than virtual.

Sub-theme 1.2: Time-consuming Checking of outputs. The choice of assessment should not be an afterthought as it may define our response to the current crisis and will affect universities' academic standards. Students' performance, marks, and final degree classification depend on assessment, and teachers have a duty to set up fair assessments in line with learning outcomes (Bretag, T., et al., 2019). Some of the participants' responses relative to the theme are as follows: 
"I'm tired of reviewing the students' online performance tasks. Each of them would submit their individual tasks. Every time I open my account, I'm faced with nearly a thousand outputs that need to be reviewed before the semester is over. "

$-(\mathrm{PE}$ TB $)$

"I'm having trouble checking my students' outputs because, aside from checking, the module contains a variety of learning exercises, and they must also upload videos of their solo performance tasks."

$-(\mathrm{PE}$ TC)

"There are times that I conduct online performance tasks. My students should perform the basic skills, and I will directly grade the task. Some of the students will attend the online performance, but other students will just send their videos online, making me allocate another time for checking."

-(PE TD)

Teacher support online involves effective monitoring of student progress, anticipation and resolution of key learning queries, and the establishment and maintenance of rapport. Collectively, these kinds of competencies shape the effectiveness of online instructors and, in turn, the student experience. Although performing online evaluations may be convenient for some physical education teachers, the checking of outputs from their learning modules and other performance tasks to be submitted online makes their job difficult. This study found that when it comes to reviewing outputs and other online-submitted performance activities, there is substantially more strain on these tasks on the part of the PE teacher when evaluation, feedback, and communication occur in a condensed timeframe.

\section{Theme 2:Online Teaching Technical Challenges}

Online Teaching Technical challenges faced by the participants are discussed, which include all essential technical elements, such as internet connectivity and the use of online tools. Poor internet connection, issues with online modalities and platforms, and online teaching distractions are the subthemes of technical challenges in online teaching.

\section{Sub-theme 2.1: Poor Internet Connection.}

The following are some of the experiences of the study's participants:

"Technical difficulties are one of the most common experiences I face in my online classes. Teachers are unable to keep up with their virtual classes because they are not equipped with the high bandwidth or strong internet connection needed for online classes. "

(PE TF)

"The main problem I faced during this pandemic's online class was a lack of internet access. In my case, I live in a signal-poor area and must get up early to get to a location where I can get a better internet connection for my online classes."

(PE TG)

"Even when I am scheduled to work from home, I must stay at the office to connect to the school's WiFi in order to conduct online classes and check my students' outputs. We do not have a strong internet connection at home."

(PE TC) 
The Philippines has the slowest Internet connection speed in Asia Pacific (The Manila Times, 2018).Since the outbreak of the pandemic (Cuaton, G.P. 2020), poor internet connectivity has been a problem in the country, and the need to shift to online education has become a pressing necessity. To support online education, it is suggested that faculty be provided with more resources and technical support. The fact that the majority of faculty members had a somewhat stable Internet connection and only a few had a very stable connection may have contributed to their apprehension toward online education. Even among college students, internet access remains a problem (Moralista, et al., 2020).

Poor internet connectivity has been a problem in the country since the outbreak of the pandemic until the need to switch to online education became a pressing necessity, according to the research. Because internet connections are so poor, the majority of professors struggle with online classes. Faculty should be given more resources and technology infrastructure to support online education, according to experts. Additionally, all faculty members should be given a data allowance to allow them to purchase high-speed internet connections.

Sub-theme 2.2: Online Teaching Modalities/Platforms used Concerns. Professors are now using a range of tools to offer course content. They are teaching their courses using online educational sites, videoconferencing tools, and social media (Patricia, 2020). The following are the experiences of the participants:

"I really have to explore more the online platforms used first, so that when it comes to online teaching, there will be no time wasted in setting up."

(PE TD)

"I need to learn other online learning tools that are more appropriate for me and my students so that they do not have to pay more money to attend online classes. Facebook Messenger, Google Meet, Google Shared Drive, and Google Classroom are the applications I use the most. " (PE TE)

"The modalities/platforms that are used in class are user-friendly; the only issue is the use of different online platforms."

(PE TJ)

Lederman (2020) correctly indicated that, as a result of the COVID-19 crisis, both teachers and students feel compelled to accept the digital academic experience as the summum bonum of the online teaching-learning process. In the higher education sector, the Commission on Higher Education (CHED, 2020) said HEIs were given academic freedom and should implement available distance learning, e-learning, and other alternative modes of delivery to students (CHED, 2020). The Commission on Higher Education recommended that online platforms and blended learning, such as Google Classroom, Messenger, Zoom, Edmodo, Facebook, and YouTube, be improved. Furthermore, both can use a range of learning delivery approaches, including face-to-face, blended learning, distance learning, home-schooling, and other forms of delivery. To encourage effective student participation, learning management systems (Google Classroom, Google Meet, Google Docs, and other Google products (Moluayonge, 2020) were used.Remarkably, students preferred blended learning as the mode of delivery in instruction (Ożadowicz, 2020; Pham \& Ho, 2020).

According to the findings of this study, teachers were trained by institutions that provided hands-on experience. It was a difficult task for the teachers to use new instructional strategies and online modalities. Teachers were initially expected to communicate with their students via a variety of convenient online channels. Teachers discovered that Google Meet, Facebook Messenger, Google Classroom, and Google 
Shared Drive were adequate online resources for providing quality education as the lockdown time was gradually extended.

Sub-theme 2.3: Online Teaching Distractions. The following are some of the participants' viewpoints:

"Since some of my students did not check their microphones before online lectures, their voices were causing unnecessary embarrassment and distraction."

(PE TC)

"Sometimes students' voices during online recitations are not clear because of poor internet connection. It led to wastage of time which could have otherwise been avoided. "

(PE TI)

During online classes, students tend not to open their cameras, and it makes me bothered because I don't know what they're doing. Maybe they are just sleeping or not paying attention.

(PE TG)

"Due to weather conditions and power interruptions, online classes were sometimes postponed or even cancelled. This made my teaching time frame for the teachers disrupted."

(PE TA)

There are a range of tools available for online education, but they can also cause a lot of problems. Elearning is reliant on technology, such as the internet and computers, which students may not have access to, and interruptions or other system errors may occur during classes (Sadeghi, 2019).

According to the results, technical distractions can be particularly difficult when you need to research or complete coursework on your phone or device. Online content can be theoretical at times, making it challenging for students to practice and learn effectively. An effective way to manage online distractions is to prerecord video lectures, check the content, and always have a Plan B on hand. These can all help to ensure that the teaching-learning process is not interrupted. Online courses should be stimulating, interactive, and dynamic. Teachers should give students time limits and reminders to keep them alert and focused.

\section{Theme 3: Personal Health Concerns}

This teacher-related health problem is likely to have long-term implications for education, offering an opportunity to reconsider instruction, teaching-learning evaluation processes, and the growth of students' competencies while improving their learning abilities and preserving their motivation. (Daniel, 2020; UNESCO, 2020 e). The participants' personal health challenges are discussed in the subsequent discussions, which include physical health concerns, mental health concerns, and social health concerns.

Sub-theme 3.1: Physical Health Concerns. Moving learning from classrooms to homes at scale and in a timely manner poses enormous human physical challenges (for example, establishing, sustaining, and enhancing distance learning, or assessing and validating learning) (UNESCO, 2020c). The following are the participants' personal health issues and their experiences:

"My back hurts every time I have online classes and review outputs because of the prolonged sitting. This left me tired for the rest of the day."

(PE TA)

"Since I was sitting in front of my laptop during online classes and whenever I reviewed emails and questions from my students, my eyes were sometimes irritated."

(PE TG) 
"During the day at work, I sit for long periods of time, which makes my body weak. As if I live with a sedentary lifestyle, I am expected to engage in sports three days a week after 5:00 p.m." (PE TB)

Spending more time on the internet is detrimental to our physical health, leading to a shift away from healthy leisure pursuits and recreational sports and toward sedentary entertainment such as television, video games, and computers (Wang et al., 2012). In an article published by Better Health, 2020, it is stated that in the new normal, radio frequency $(\mathrm{RF})$ radiation is used by mobile phones and other gadgets to communicate with base stations. When RF radiation is strong enough, it has a 'thermal' effect, meaning it raises body temperature. Low levels of RF radiation emitted by mobile phones and other gadgets have been linked to health issues such as headaches and brain tumors.

It is inferred that although online teaching and learning make it easier for students and teachers to access education, it potentially leads them to a sedentary lifestyle and related health issues. Similarly, the role of physical activity in the general health and well-being of teachers during lockdown should be considered, as it has been discovered that teachers who exercise more during leisure time or in a more autonomous manner may be able to prevent physical and mental health problems more easily.

\section{Sub-theme 3.2: Mental Health Concerns}

The following are the obstacles that the participants faced in terms of mental wellbeing:

"I'm just concerned because a lot of students in my class dropped out within the first month of the semester. Their reasons are financial, they don't have any gadgets, and they can't fulfill all of the requirements, which initially depressed me."

(PE TH)

"I am stressed because I am disengaged from my students' ability to grow with this online teaching. This made me fear that I am not an effective teacher."

(PE TA)

Faculty members are under a lot of pressure to convert their classes to digital formats that are effective. The additional workload, as well as the anxiety that comes with it, is added to faculty's already complex responsibilities. Concerns about faculty burnout have grown as a result of the increased workload. Due to the demands of teaching, advising, research, and publication, many faculty members who are already on the verge of burnout face an emotional letdown or even collapse (Schroeder,2020). As a result, it is common for teachers to feel more overwhelmed and nervous in such unprecedented and unpredictable times. Teachers do, in fact, require socio-emotional support in order to cope with the external stresses placed on them in order to provide learning in a crisis (UNESCO, 2020d).

The study emphasizes that mental health is one of the most underserved aspects of public health. Mental health issues are important for all teachers to be aware of because they not only have a detrimental effect on themselves but also have a direct impact on classroom outcomes.

Sub-theme 3.3: Social Health Concerns. Teachers find it difficult to teach online because they have no way of knowing how well their students are grasping course material or participating in learning activities. One of the most important aspects of effective online education, according to Karen Quevillon (2020), is student engagement. Collaborative participation encourages learning and allows for a more in-depth and analytical understanding of the material. Collaboration is one of the most difficult things to achieve 
because students are not physically present together. Some of the participants' responses to the case are as follows:

"I had little time to enjoy my social life when teaching via online sessions. It is, however, a necessary part of my job. I feel like I'm constantly busy planning modules and online tutorials, and most of the time I've lost contact with my coworkers and family at home."

(PE TB)

"Active interactive sessions such as team-based learning, peer teaching, and group discussion among students were all things I missed. I still prefer face-to-face classes. "

(PE TC)

"Online teaching keeps me away from my students, and it feels like I am always busy preparing my learning modules, instructional videos, and checking their outputs."

(PE TG)

It is difficult to keep students engaged during online lectures without a teacher's physical presence and face-to-face touch. Furthermore, a major problem is associated, and it is difficult to put into practice without in-person training and courses that rely heavily on hands-on experience. Online learning, if not carefully planned, may turn students into passive observers rather than active participants. Even if these disinterested students understand the lecture material, they are unable to apply what they have learned outside of the virtual setting (Charalampous et al., 2019).

The study underscored that faculty members are now in charge of recognizing social health problems on the front lines. In most cases, no one else is keeping an eye on the students. In order to work with all learners or students in individualized and close relationships, all teachers should be prepared in all teaching roles for flexible learning. They must play a significant role in daily work and face-to-face with them. When this direct contact is replaced by an online relationship, the work becomes even more difficult, and many other factors must be considered.

\section{COPING MECHANISM IN ONLINE TEACHING}

While it is acknowledged that face-to-face teaching competencies such as knowledge of curricula and pedagogy do transfer to online contexts, it is also important to recognize the unique competencies required for online teaching success and the role of institutions in setting instructor duties and responsibilities. During the pandemic, the participants described coping mechanisms in teaching PE. These were explored under the following themes: Possess a Positive Outlook; Learn to Adjust to the Situation; and Provide Alternative Teaching Methods.

\section{Theme 1: Possess Positive Outlook}

Teachers have always played a vital role in introducing reform-based innovations (e.g., online or virtual teaching, distance education, flexible learning). According to Semerci and Aydin (2018), attitude is a factor that affects an individual's actions based on his feelings and thoughts. The following are some of the participants' responses:

"I need to figure out how to overcome the obstacles I've encountered, because if I don't, I'll be the one who suffers. I'm a teacher who likes to think positively, and I still strive to remove the bad and negative things from my life, which I believe has helped me resolve my teaching difficulties. I'm concentrating on being positive and doing what is right, healthy, and beneficial to myself."'-PE TJ 
"I simply deal with it and face it with a strong heart and an open mind, telling myself that I must complete all of the challenges."- (PE TD)

"My method of problem-solving is to simply relax and think quickly about a solution in order to stay organized and centered. This problem will be as simple as it is."-(PE TB)

As Keeton (2004) explained, the positive attitude of teachers toward virtual teaching will help build a positive online environment, the findings of this study are a good indication. Furthermore, a lack of training may lead to teachers' lack of confidence in digital learning, leading to teachers' unwillingness or resistance to adopting best practices (Baran et al. 2011). The positive attitude of the teacher will create a virtual environment that will most likely motivate students to learn online.

The researcher discovered that heightened faculty members' attitudes toward internet-based education, as well as their perceptions of their level of computer and internet access, preparation for time commitments required for online teaching, level of institutional support, level of computer and internet skills, and perceived importance of education. Faculty members appeared to be optimistic about internet-based distance education.

\section{Theme 2: Learn to Adapt with the Situation}

As a result of COVID-19, schools are now looking for an online platform that can be used by both teachers and students to help them excel. Unfortunately, moving to online learning after decades of dismissal is not as easy as one would expect. A lot more planning and preparation is required than in a typical face-to-face course (Baran et al. 2013). The following are some of the answers from the participants:

"I just live with it - I have no choice but to ADOPT AND ADAPT. I just want my students to learn and pass the course despite the pandemic; I have to accept it, even though it hurts me." (PE TD)

"I always look for essential things that would help myself get up and be productive. I always tell myself to not procrastinate things. As the time goes by, I just learned how to manage my time effectively as being a teacher and a student at the same time."

(PE TB)

"One way of solving these challenges is time management. Providing enough time to finish each activity on time. Taking one by one step and prioritizing this are just some that helped and will help me accomplish things."

(PE TG)

"Online teaching is one of the ways and means that we need to comply in order not to stop the teaching and learning process. That's why, I learn to adapt with the situation just to deliver learnings to my students as well as to make them safe from the threat of COVID."

(PE TE)

An online teacher must create a coherent learning experience for students with whom they may not meet face-to-face and, therefore, must develop new support strategies that maintain motivation and encourage interaction. Adapting student-centered approaches to the online environment has required the development of new skills and changes to teaching practices. According to the findings, although most Physical Education teachers face challenges in adapting to online learning, adaptation is an important strategy in educational settings because it enhances relationships among students, teachers, and institutions. This will improve educational opportunities for teachers who are juggling school, job, and family commitments, as well as other issues. 


\section{Theme 3: Provide Alternative Means}

Various institutions were forced to change their workflow strategies and adopt new technologies as a result of the pandemic. In the majority of cases, these organizations did not have enough time to consider how new strategies and related technologies should be introduced and integrated into their current setup (Carroll \& Conboy, 2020). In times of emergency, provide alternative modes of learning and education in educational institutions, as well as equivalency and bridging programs that are recognized and accredited by the state (R. H. Huang et al., 2020). Some of the participants discussed the following scenario:

"Despite the difficulties of the situation, I actively motivate my students to pass and complete the subject's requirements. If students fail to attend an online class, I record the meeting and, on occasion, video record it and upload it to our group chat so that they can view the subject online. "

(PE TA)

"In order for students who skipped the online class to learn more from the videos, I have to provide detailed instructional videos and lecture notes while teaching PE. In addition, in all performance activities, I include specific criteria and rubrics so that they can be directed."

(PE TD)

"What we need is to understand the circumstances as well as provide alternative methods of completing tasks. I provide a range of teaching methods that do not require a class to be set up online."

(PE TG)

"I practice using different gadgets and designing various suitable activities for students' better understanding. I admit that the usage of online teaching will test both the educator and the learners. That's why I am exploring other learning platforms that are more useful and stressfree for me and my students. "

(PE TH)

Much of teaching and learning in an online environment is similar to teaching and learning in any other formal educational context. Online learning and teaching involve a diverse array of tools, resources, pedagogical approaches, roles, organizational arrangements and forms of interaction, monitoring and support - with many possible combinations of substitution and integration (Bates and Poole, 2003; Bullen and Janes 2007; Bach, Haynes and Smith 2007). It includes a variety of tools, services, organizational structures, modes of engagement, tracking, and support, as well as numerous replacement and support options (Bates and Poole, 2003; Bullen and Janes, 2007; Bach, Haynes, and Janes, 2007; Bach, Haynes, and Janes, 2007; Bach, Haynes, and Janes, 2007; Bach, Haynes, and Jane Smith, 2007).

In the COVID-19 situation, teachers use techniques to act as designers and tutors overnight. The importance of designing effective learning environments and instructional tools as an alternative means rests not only upon the shoulders of faculty but also upon institutions of higher education more generally in the form of support (funding) for faculty professional development.

\section{Conclusion}

In times of pandemic, teaching physical education faces specific challenges, such as methodological issues, technical issues, personal health concerns, and other institutional methodology barriers. The pressure that online educational methods have placed on teachers has led to major problems in their lives, as evidenced by the many hours of work and difficulties caused by a lack of physical contact or the obstacles created by 
combining personal and family life. Making meaning during the pandemic, learning from the past, and reimagining the future given a present full of losses, according to the positive findings of adaptability, reflexivity, and optimism during COVID-19, suggests that making meaning during the pandemic, learning from the past, and reimagining the future given a present full of losses are important to developing resilience and hope during these trying times. In addition to these roadblocks, a solution for instructional methods, technical readiness to incorporate online learning, and providing support and encouragement to all parties involved must be developed. Education must be viewed in a positive light.

\section{Recommendations}

The findings of this research support the evidence regarding the effectiveness of online teaching for physical education teachers. However, it is important to realize that it is not the only mode of transferring efficient knowledge. Thus, online teaching predominately synchronized learning represents a meaningful and promising potential for the students, especially the Bachelor of Physical Education, and can be integrated into the curriculum to enhance its effectiveness for lifelong learning. There is a need for research to identify other effective online and offline teaching modalities and to formulate a meticulous model through the integration of an optimal proportion of online learning. The intervention plan for teaching physical education in pandemic situations will be used and will serve as the framework for an enhanced implementation of teaching pedagogies, learning design, and online teaching in physical education, especially in times of extraordinary circumstances. Approaches to adjusting to the current situation of teaching physical education classes that highlight each educational characteristic must be checked and systematized, and the usefulness of online physical education classes as a whole must be investigated for future research.

\section{REFERENCES}

Abdulamir, A. S. \& Hafidh, R. R. (2020). The Possible Immunological Pathways for the Variable Immunopathogenesis of COVID-19.

Adnan, M. and Anwar, K. (2020). Online learning amid the COVID-19 pandemic: student's perspectives. J. Pedagogic. Res. 1, 45-51.

Adedoyen, P. and Soylen (2020). UST Implements 'Enriched Virtual Mode' Next Academic Year; Extends Financial Assistance. Manila, PH: Tomasino Web.

Ali, W. (2020). Online and remote learning in higher education institutes: A necessity in light of COVID-19 pandemic. Higher Education Studies, 10(3), 16-25.

Ateneo de Manila University (2020). Adaptive Design for Learning (ADL). Quezon City, PH: Ateneo Salt Institute.

Azzahra, N. F. (2020). Addressing Distance Learning Barriers in Indonesia amid the COVID-19 Pandemic. South Jakarta: Center for Indonesian Policy Studies.

Bagayas, S. (2020). Students Of Top 4 PH Schools Urge CHED To Suspend Online Classes. Pasig, PH: Rappler.

Baggaley, J. (2008). Where did distance education go wrong? Dist. Educ. 29, 39-51. doi: 10.1080/01587910802004837

Bandalaria, M. D. P. (2019). Massive open online courses as open educational resources in a blended teaching and learning mode of instructional delivery in higher education. Intern. J. Innov. Learn. 25:156. doi: 10.1504/ijil.2019.10018278 
Basalaia, $\mathrm{H}$ and Kvavadzae J., (2020b). Schools Gear Up to Reopen Nationally. Available online at: https://www.bangkokpost.com/thailand/general/1928892/schools-gear-up-to-reopen-nationally (accessed October 6, 2020).

Bates, A. W., \& Poole, G. (2003). Effective teaching with technology in higher education. San Francisco: Jossey-Bass.

Biana, H. (2013). Reaching the unreached: philippine distance education and dislocation. J. Worldwide Forum Educ. Cult. 4, 73-84.

Braun, V., \& Clarke, V. (2006). Using thematic analysis in psychology. Qualitative Research in Psychology, 3(2), 77101.

Bretag, T., Harper, R., Burton, M., Ellis, C., Newton, P., van Haeringen, K., Saddiqui, S., and Rozenberg, P. (2019b). Contract cheating and assessment design: exploring the relationship. Assessment and Evaluation in Higher Education, 44(5):676-691.

Bryson, J. R., \& Andres, L. (2020). Covid-19 and rapid adoption and improvisation of online teaching: curating resources for extensive versus intensive online learning experiences. Journal of Geography in Higher Education, 44(4), $608-623$.

Bullen, Mark \& Janes, Diane. (2006). Making the Transition to E-Learning: Strategies and Issues. 10.4018/978-1-59140950-2.

Cai, R.;Wang, Q.; Xu, J.; Zhou, L. Effectiveness of Students' Self-Regulated Learning during the COVID-19 Pandemic. Sci Insigt 2020, 175-182.

Carroll, N., \& Conboy, K. (2020). Normalising the "new normal": Changing tech-driven work practices under pandemic time pressure. International Journal of Information Management, 102186. In Press. https://doi.org/10.1016/j.ijinfomgt.2020.102186

Charalampous et al., 2019, Systematically reviewing remote e-workers' well-being at work: A multidimensional approach European Journal of Work and Organizational Psychology, 28 (1) (2019), pp. 51-73.

Chulalongkorn University (2020). Chulalongkorn University Introduces Online Learning Innovation Center . Available online at: https://qswownews.com/chulalongkorn-university-introduces-online-learning-innovationcenter/ (accessed October 5, 2020).

Commission on Higher Education (2020). COVID-19 Updates - Advisory 6. Quezon City, PH: CHED.

Cuaton, G.P. (2020). Philippines higher education institutions in the time of COVID-19 pandemic. Revista Românească pentru Educaţie Multidimensională, 12(1).

Czerniewicz, L., 2020. What we learnt from "going online" during university shutdowns in South Africa. [Online] Available at: https://philonedtech.com/what-we-learnt-from-goingonline-during-university-shutdowns-in-southafrica/.

De Vera, P. (2020a). Statement on the News Report from Rappler. Quezon City, PH: CHED.

De Vera, P. (2020b). Universities, Colleges Gear Up For Opening Of Classes in August. Quezon City, PH: CHED.

Department of Education (2020). Learning While Staying At Home: Teachers, Parents Support DepEd Distance Learning Platform. Pasig City, PH: DepEd.

DQ Institute (2019). Outsmart the Cyber-pandemic: Empower every child with digital intelligence by 2020. Retrieved from file:///D:/COVID/DQEveryChild\%20DQ\%20Institute.html.

Dubey, P., \& Pandey, D. (2020). Distance learning in higher education during pandemic: challenges and opportunities. The International Journal of Indian Psychology, 8(2), 43-46. 
Edge, W. D., and Loegering, J. P. (2000). Distance education: expanding learning opportunities. Wildlife Soc. Bull. 28, 522-533.

Eyal, N., with Li, N. (2019) Indistractable: How to Control Your Attention and Choose Your Life. New York, NY: Bloomsbury Publishing.

Flores, J. B. (2018). Virtual learning platform with short message service (SMS) notification. J. Sci. Eng. Technol. 6, 8295.

FutureLearn. (March 19, (2020)). COVID-19: The best resources for online teaching during coronavirus. Retrieved from file:///D:/COVID/COVID-0FutureLearn.html.

Guri-Rosenblit, S. (2005). 'Distance education' and 'e-learning': not the same thing. High. Educ. 49, 467-493. doi: $10.1007 / \mathrm{s} 10734-004-0040-40$

Hooks, b. (2003). Teaching Community: A Pedagogy of Hope. New York, NY: Psychology Press.

Hoy, C., Bayne-Jardine, C. and Wood, M. (2000) Improving Quality in Education, London, Falmer Press.https://www.sunstar.com.ph/article/1866689/Cebu/Local-News/Parents-Slow-internet-affects-onlineclasses

Jakarta Globe (2020). Education Ministry Teams Up with TVRI To Deliver Distance Learning. Jakarta: Jakarta Globe.

Jones, N. (2019). Improving Internet Access in the Philippines. San Francisco, CA: Asian Foundation.

K. Vishnu, B. Nithyaja, C. Pradeep, R. Sujith, P. Mohanan, and V. Nampoori, "Studies on the effect of mobile phone radiation on DNA using laser induced fluorescence technique," Laser Physics, vol. 21, no. 11, pp. 1945-1949, 2011.

Keeton, M. T. (2004). Best online instructional practices: Report of phase I of an ongoing study. Journal of Asynchronous Learning Networks, 8, 75-100.

Larreamendy-Joerns, J., and Leinhardt, G. (2006). Going the distance with online education. Rev. Educ. Res. 76, 567605. doi: $10.3102 / 00346543076004567$

Lederman, D. (2020)(March 18, Will shift to remote teaching be boon or bane for inline learning? Inside Higher Ed. Retrieved from file:///D:/COVID/.html.

Lich, T. (2020). E-learning Apps Expand, Users Adapt To Distance Learning. TienPhong News. Available online at: https://tienphongnews.com/e-learning-apps-expand-users-adapt-to-distance-learning-13862.html (accessed October 6, 2020).

L. M. Hollestein and T. Nijsten, "An insight into the global burden of skin diseases," Journal of Investigative Dermatology, vol. 134, no. 6, pp. 1499-1501, 2014.

Magsambol, B. (2020). FAST FACTS: DepEd’s Distance Learning. Pasig, PH: Rappler.

Moluayonge, G. (2020). The Use of Modern Educational Technologies in Remote Learning in Higher Education During a Pandemic: The Case of COVID-19 in Cameroon. Journal of Learning for Development, 7(3), 479-484.

Murphy, M. P. (2020). COVID-19 and emergency eLearning: Consequences of the securitization of higher education for post-pandemic pedagogy. Contemporary Security Policy, 41(3), 492-505.

Ożadowicz, A. (2020). Modified Blended Learning in Engineering Higher Education during the COVID-19 LockdownBuilding Automation Courses Case Study. Education Sciences, 10(10), 292.

Patton, M. Q. 2002. Qualitative research and evaluation methods, , 3rd ed, Thousand Oaks, CA: Sage Publications.

Rasmitadita, A. J., Nangit, G., Ranga, A. I., and Triñona, J. (2007). ICT-enabled distance education in community development in the Philippines. Dis. Educ. 28, 213-229. doi: 10.1080/01587910701439258 
Raes, A., Detienne, L., Windey, I., \& Depaepe, F. (2019). A systematic literature review on synchronous hybrid learning: Gaps identified. Learning Environments Research, published online 28 November 2019.

Ritonga, A.W., Ritonga, M., Nurdianto, T., Kustati, M., Rehani, Lahmi, A., Yasmadi, Pahri (2020). E-learning process of maharah qira'ah in higher education during the covid-19 pandemic. International Journal of Higher Education, 9(6), 227-235.

Moralista,R. Oducado, R.M. , "Faculty Perception toward Online Education in a State College in the Philippines during the Coronavirus Disease 19 (COVID-19) Pandemic," Universal Journal of Educational Research, Vol. 8, No. 10, pp. 4736 - 4742, 2020. DOI: 10.13189/ujer.2020.081044.

Sadeghi, M. A Shift from Classroom to Distance Learning: Advantages and Limitations. Int. J. Res. Engl. Educ. 2019, 4, $80-88$.

Schroeder. R, 2020 https://www.insidehighered.com/digital-learning/blogs/online-trending-now/wellness-and-mentalhealth-2020-online-learning.

Semerci, A. and Aydin, M. (2018). Examining High School Teachers' Attitudes towards ICT Use in Education. International Journal of Progressive Education, 14(2), pp. 93-105.

The Manila Times. (2018). PH's economic competitiveness: is slow Internet a factor? Available at https://www.manilatimes.net/2018/06/03/business/phs-economic-competitiveness-is-slow-internet-a-factor.

UNESCO (2020). Education: from Disruption to Recovery. Paris: UNESCO.

UNESC.(2020c). Adverse Consequences of School Closures. Available online at: https://en.unesco.org/covid19/educationresponse/consequences (accessed June 5, 2020)

UNESCO (2020d). COVID-19 Webinar: A New World for Teachers, Education's Frontline Workers - COVID-19 Education Webinar \#2. Available online at: https://en.unesco.org/news/covid-19-webinar-new-world-teacherseducations-frontline-workers-covid-19-education-webinar-2 (accessed June 5, 2020)

University of Santo Tomas (2020). Institutional Continuity Plan during Extended and Post-ECQ. Manila, PH: University of Santo Tomas.

University of the Philippines - College of Education (2020). Education Resilience and Learning Continuity Plan. Quezon City, PH: University of the Philippines - College of Education.

Villarin, J. R. T. (2020). Enhanced Community Quarantine. Quezon City, PH: Ateneo de Manila University.

Wang, L., Luo, J., Gao, W., \& Kong, J. (2012). The effect of internet use on adolescents' lifestyles: a national survey. Computers in Human Behavior, 28, 2007-2013.

Yamin, K. (2020). Mixed Response but Online Classes to Stay Post COVID-19. London: University World News. 